\title{
Отделение эпитаксиальных гетероструктур III-N/SiC от подложки Si и их перенос на подложки других типов
}

\author{
(C) С.А. Кукушкин ${ }^{1,2,3}$, А.В. Осипов ${ }^{1,2}$, А.В. Редьков ${ }^{1,3}$ \\ ${ }^{1}$ Институт проблем машиноведения Российской академии наук, \\ 199178 Санкт-Петербург, Россия \\ ${ }^{2}$ Санкт-Петербургский национальный исследовательский университет \\ информационных технологий, механики и оптики, \\ 197101 Санкт-Петербург, Россия \\ ${ }^{3}$ Санкт-Петербургский политехнический университет Петра Великого, \\ 195251 Санкт-Петербург, Россия \\ E-mail: avredkov@gmail.com
}

(Получена 12 июля 2016 г. Принята к печати 17 августа 2016 г.)

Разработан метод отделения и переноса эпитаксиальных гетероструктур GaN/AlN и AlN, выращенных на кремнии с буферным слоем карбида кремния, на подложки любых типов, основанный на химическом травлении. Гетероструктуры $\mathrm{GaN} / \mathrm{AlN} / \mathrm{SiC}$ толщиной 2.5 мкм и $\mathrm{AlN} / \mathrm{SiC}$ толщиной 18 мкм отделены и перенесены на стеклянную подложку. Показано, что буферный слой карбида кремния на кремнии, выращенный методом замещения атомов, имеет развитую подповерхностную структуру, которая позволяет легко отделить пленку от подложки и способствует релаксации упругой энергии, вызванной различием в коэффициентах теплового расширения пленки и подложки. Показано, что после отделения пленки от подложки кремния механические напряжения в пленке практически полностью релаксировали.

DOI: 10.21883/FTP.2017.03.44218.8368

\section{1. Введение}

Основными полупроводниковыми материалами, использующимися для производства приборов силовой электроники в настоящее время, являются: кремний $(\mathrm{Si})$, арсенид галлия (GaAs), карбид кремния $(\mathrm{SiC})$, и нитрид галлия $(\mathrm{GaN})[1-3]$. В основном предпочтение отдается таким материалам, как $\mathrm{SiC}$ и $\mathrm{GaN}$, поскольку они значительно превосходят по ряду физических параметров $\mathrm{Si}$ и GaAs. Например, напряженность электрического поля пробоя в $\mathrm{SiC}$ и $\mathrm{GaN}$ (электрическая прочность) на порядок выше, чем у кремния или арсенида галлия. $\mathrm{SiC}$ и $\mathrm{GaN}$ обладают высокой радиационной стойкостью $[4,5]$. Еще одной очень важной особенностью широкозонных полупроводниковых материалов, к которым относятся $\mathrm{SiC}, \mathrm{GaN}$ и нитрид алюминия (AlN), является высокая предельная рабочая температура $p$-n-перехода, допустимая при эксплуатации приборов, изготовленных на их основе. Эта температура достигает значений $300-500^{\circ} \mathrm{C}$, что значительно выше, чем для приборов, имеющих в своей основе кремний. GaN может быть применен для изготовления транзисторов с высокой подвижностью носителей заряда - так называемых НЕMT [6], работающих на частотах 150 ГГц и выше, что открывает беспрецедентные возможности для создания приборов нового типа. Очень высокая концентрация электронов в области двумерного электронного газа в сочетании с их приемлемой подвижностью дает возможность реализовать бо́льшую плотность тока в сечении канала транзистора и соответственно больший коэффициент усиления.

Существенной проблемой, сдерживающей развитие приборов на $\mathrm{GaN}$, является проблема обеспечения эффективного теплоотвода от активной области гетеро- структуры. Для решения данной задачи исследователи пытаются вырастить эпитаксиальные структуры на основе $\mathrm{GaN}$ на чужеродных (отличающихся по параметрам кристаллической решетки, тепловому расширению и т.д.) подложках $[7,8]$. Однако этот путь сложен и во многих случаях весьма дорогостоящий. Отметим, что сапфировые подложки [9] мы здесь не рассматриваем по причине их низкой теплопроводности.

Одним из возможных способов выращивания гетероструктур для мощных НЕМТ является использование в качестве подложки для роста $\mathrm{GaN}$ монокристаллов $\mathrm{SiC}$. Теплопроводность этого материала близка к теплопроводности меди. Кроме того, параметры решетки $\mathrm{SiC}$ весьма близки к параметрам решеток $\mathrm{GaN}$ и $\mathrm{AlN}$ [10]. Это позволяет предположить (и не только предположить, поскольку подложки $\mathrm{SiC}$ уже широко используются на практике [11]), что использование $\mathrm{SiC}$ в качестве подложки для роста гетероструктур на основе AIN и $\mathrm{GaN}$ весьма перспективно. Тем не менее существенным недостатком использования монокристаллов $\mathrm{SiC}$ при изготовлении приборов является высокая цена подложек $\mathrm{SiC}$ хорошего качества и необходимого политипа.

Один из возможных путей преодоления данной проблемы мы видим в использовании тонкого и дешевого в производстве эпитаксиального слоя $\mathrm{SiC}$, выращенного на подложке $\mathrm{Si}$. В цикле работ, обобщенных в обзоpax [12-14], были проведены исследования по разработке и созданию нового типа подложечного материала для изготовления на его основе различных типов полупроводниковых приборов и интегральных микросхем нового поколения на основе широкозонных полупроводников. В результате этих работ был теоретически предсказан и экспериментально подтвержден принципиально 
новый способ выращивания очень тонкого, толщиной до 100 нм, эпитаксиального слоя нанокарбида кремния на кремнии. Метод основан на замещении части атомов в кремнии на атомы углерода без разрушения кремниевой основы [13]. По сути дела впервые в мировой практике реализован метод последовательной замены атомов одного сорта другими прямо внутри исходного кристалла без разрушения его кристаллической структуры. Качество структуры слоев, полученных данным методом, весьма высокое и значительно превосходит качество пленок карбида кремния, выращенных на кремниевых подложках традиционными методами. При этом самое главное, что метод дешев и технологичен.

Простота реализации и низкая себестоимость такого буферного слоя $\mathrm{SiC} / \mathrm{Si}$, превышающая средние затраты на производство кремниевой пластины того же диаметра менее чем в 2 раза, снижают себестоимость всех выращиваемых на нем материалов и структур. При этом, как было показано в [13], кремний под слоем $\mathrm{SiC}$, созданным методом замещения атомов, содержит множество пор, в результате механические напряжения в слое $\mathrm{SiC}$, вызванные как рассогласованием решеток, так и разностью коэффициентов термического расширения $\mathrm{SiC}$ и $\mathrm{Si}$, относительно малы. Поэтому пленки AlN и GaN [15] на таком буферном слое вырастают более качественными и содержат меньше дефектов, чем на обычных пластинах кремния и даже на некоторых пластинах монокристаллического карбида кремния.

Поскольку $\mathrm{SiC}$, как было указано выше, обладает высокой теплопроводностью, встает следующий естественный вопрос: возможно ли отделить от кремниевой основы и без разрушения целиком перенести слой $\mathrm{SiC}$ с пленкой $\mathrm{AlN}, \mathrm{GaN}$ или гетероструктурой $\mathrm{AlN} / \mathrm{GaN}$, например, на медную ленту, стекло, кварц или любую другую подложку, в том числе и на пленку, изготовленную на основе из полимеров?

Нахождение ответа на этот вопрос и является целью работы. Решение данной проблемы может открыть беспрецедентные условия для создания нового типа электронных приборов. Насколько нам известно, существует всего несколько работ [16-18], в которых авторы описывали процесс отделения пленок $\mathrm{AlN}$, выращенных на кремнии, карбиде кремния и сапфире от подложки. При этом они использовали как метод плазмохимического реактивного травления [18], так и обычное химическое травление [17]. Существенным отличием нашей структуры является наличие буферного слоя $\mathrm{SiC}$, лежащего на пористой поверхности подложки $\mathrm{Si}[13,14]$. Буферный слой $\mathrm{SiC}$, с одной стороны, позволяет выращивать качественные пленки AIN и гетероструктуры $\mathrm{GaN} / \mathrm{AlN}$, а с другой, он находится на недорогой и легко стравливаемой стандартными методиками подложке Si. Благодаря особой пористой структуре подложек $\mathrm{SiC} / \mathrm{Si}$ нет необходимости использовать дорогой процесс реактивного травления, а сам процесс травления при комнатной температуре длится всего несколько минут.
Рассмотрим этот вопрос подробнее. В первой части работы рассматривается методика отделения пленок $\mathrm{GaN} / \mathrm{AlN} / \mathrm{SiC}$ и $\mathrm{AlN} / \mathrm{SiC}$ от подложки, а во второй обсуждаются свойства как пленок $\mathrm{GaN}$ и $\mathrm{AlN}$, так и структуры $\mathrm{SiC}$ в $\mathrm{Si}$.

\section{2. Методика эксперимента}

Для роста пленок $\mathrm{GaN}$ и AlN были выбраны пластины кремния ориентации (111) р-типа проводимости с сопротивлением 1000 Ом · см, на которых предварительно был выращен буферный слой карбида кремния методом замещения атомов [13]. Рост карбида происходил в атмосфере монооксида углерода (СО) с содержанием силана $\left(\mathrm{SiH}_{4}\right) 25 \%$ при давлении в 2 Торр. Температура в реакторе составляла $1250^{\circ} \mathrm{C}$, а длительность процесса роста - 20 мин. По данным эллипсометрии толщина осажденной пленки $\mathrm{SiC}$ составила $\sim 100$ нм.

Далее на одну из пластин $\mathrm{SiC} / \mathrm{Si}$ была нанесена посредством HVPE-процесса (hydride vapor phase epitaxy) [19] тонкая пленка AlN при температуре $1080^{\circ} \mathrm{C}$ и соотношении потоков $\mathrm{NH}_{3} / \mathrm{H}_{2} 1: 5$. Толщина полученного слоя AlN составила 18 мкм.

На другую пластину, используя технику, предложенную в работе [15], нанесли зародышевый слой AlN, поверх которого затем методом CVD (chemical vapor deposition) был осажден слой $\mathrm{GaN}$ толщиной 2.5 мкм по данным эллипсометрии.

Затем полученные образцы были подвергнуты химическому травлению в растворе, содержащем смесь азотной и плавиковой кислот, а также воду в соотношении $4: 1: 5$ соответственно. Такая смесь эффективно удаляет кремний [17]. Травление происходило в течение 15-20 мин при температуре $20^{\circ} \mathrm{C}$, после чего на обоих образцах пленка полностью отделилась от подложки.

Затем полученные пленки исследовались на сканирующем электронном микроскопе, далее были перенесены на стеклянную подложку и анализировались на рамановском конфокальном микроскопе Witec Alpha 300R.

\section{3. Экспериментальные результаты}

На рис. 1,2,3 представлены полученные методом сканирующей электронной микроскопии (СЭМ) изображения скола пленок $\mathrm{AlN} / \mathrm{SiC}$ и GaN/AlN/SiC до и после травления.

Рамановские спектры обеих гетероструктур представлены на рис. 4. Также для сравнения представлены их исходные спектры, измеренные до отделения от подложки. Для структуры $\mathrm{AlN} / \mathrm{SiC}$ ввиду ее существенно большей, чем размер пятна лазера, толщины спектры были сняты как со стороны $\mathrm{SiC}$, так и со стороны AlN. Ha рамановских спектрах отделенных пленок линии кремния практически отсутствуют, поскольку весь кремний в подповерхностной области был растворен, и присутствуют только линии, соответствующие $\mathrm{SiC}, \mathrm{AlN}$ и $\mathrm{GaN}$. 


\section{4. Обсуждение}

\section{1. Механизм перенесения гетероструктур на другие подложки}

Механизм перенесения гетероструктур AlN и GaN на другие подложки и получения их в свободном виде схематично изображен на рис. 5. Первым этапом является нанесение буферного слоя карбида кремния на кремний методом [13], в результате чего под поверхностью появляется развитая сеть каналов и пор. После этого на поверхность подложки $\mathrm{SiC} / \mathrm{Si}$ осаждается требуемая гетероструктура традиционными методами (HVPE, CVD, MBE - molecular beam epitaxy). В частности, в работе [15] предложена техника получения высококачественных слоев $\mathrm{GaN}$ на таких подложках методом MOCVD (metalloorganic chemical vapor deposition). 3a-
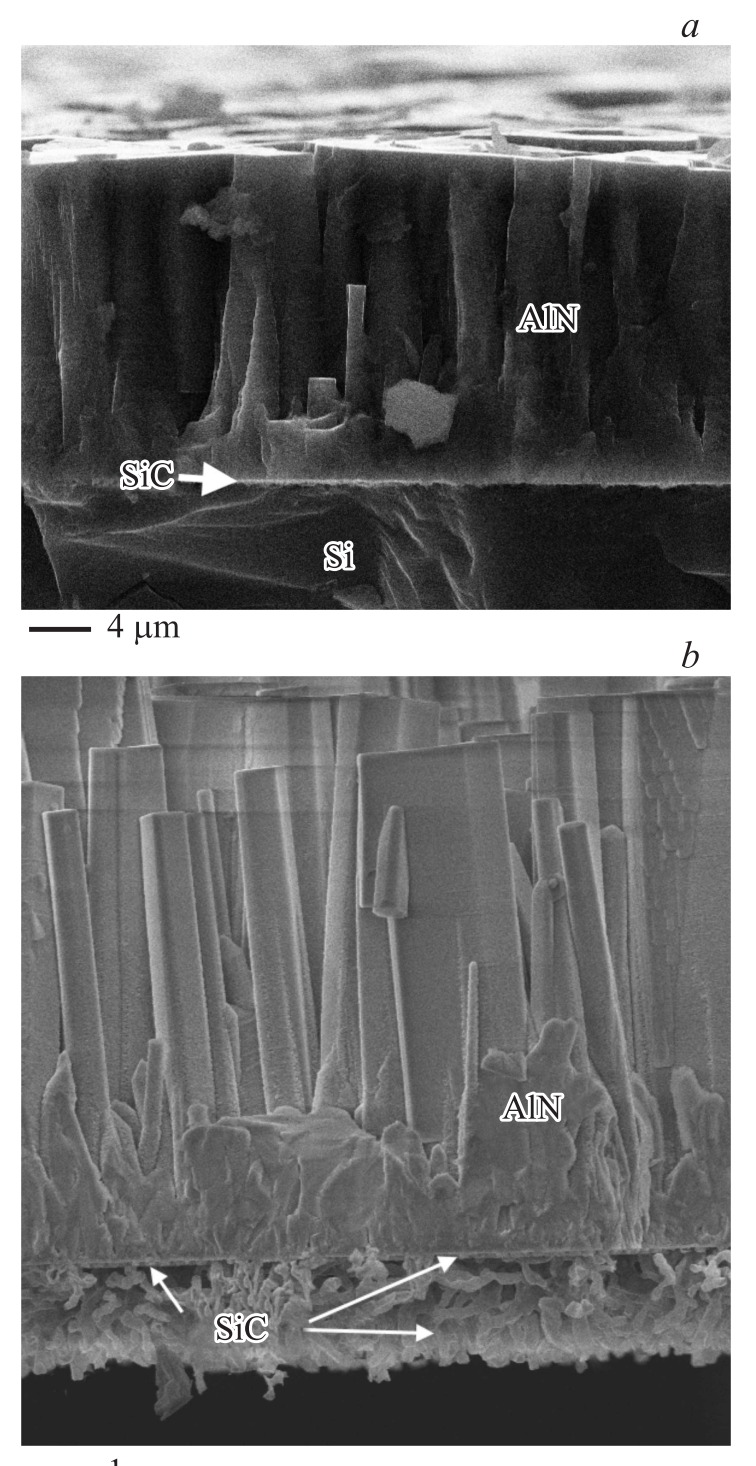

$-1 \mu \mathrm{m}$

Рис. 1. СЭМ-изображения сколов гетероструктуры $\mathrm{AlN} / \mathrm{SiC} / \mathrm{Si}$ до травления $(a)$ и тонкой пленки $\mathrm{AlN} / \mathrm{SiC}$ после травления $(b)$.
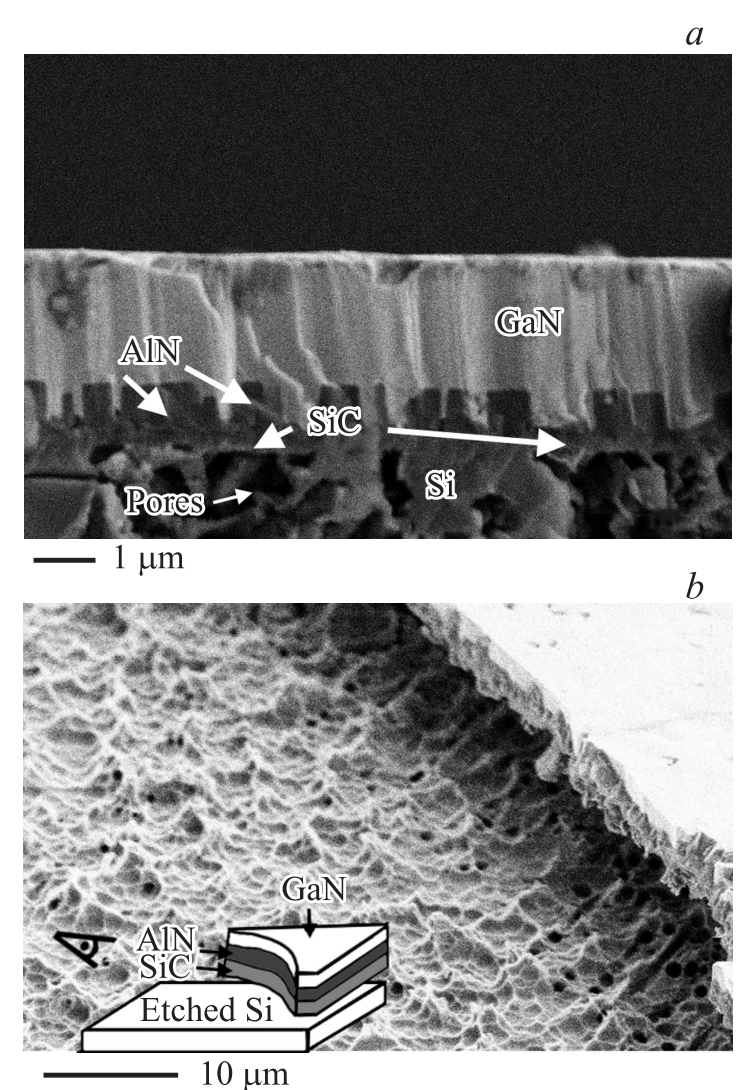

Рис. 2. СЭМ-изображения скола гетероструктуры $\mathrm{GaN} / \mathrm{AlN} / \mathrm{SiC} / \mathrm{Si}$ до травления $(a)$ и поверхность кремния после травления с находящейся на ней структурой GaN/AlN/SiC $(b)$. На вставке $(b)$ - геометрия снимка.

тем полученная гетероструктура $\mathrm{III}-\mathrm{N} / \mathrm{SiC} / \mathrm{Si}$ погружается в раствор кислоты. Через 1-5 мин после начала травления невооруженным глазом становится видно, что по краям образца пленка начинает отслаиваться от подложки. Дальше со временем фронт отслоения движется к центру, пока пленка целиком не отделится от подложки кремния (см. рис. 5). Подобное поведение обусловлено большим количеством пор и каналов в приповерхностной области кремния, которые быстро заполняются кислотой и позволяют ей проникнуть вглубь, растравливая лишь небольшие объемы кремния, находящиеся между порами. При этом не требуется растворять всю подложку кремния целиком, и процесс отделения занимает лишь несколько минут. Как правило, это время составляет при комнатной температуре 5-20 мин. Далее отслоившаяся структура может быть перенесена на другую подложку или использоваться в свободном виде. Следует отметить, что после травления пленка плавает в жидкой фазе и ею легко манипулировать с помощью пинцета. Однако делать это следует аккуратно, поскольку толщина пленки невелика и она легко разрушается. $\mathrm{B}$ нашем эксперименте пленка $\mathrm{AlN} / \mathrm{SiC}$ толщиной 18 мкм сохранила исходную форму подложки и не разрушилась, тогда как пленка GaN/AlN/SiC толщиной в 2.5 мкм при 
$a$

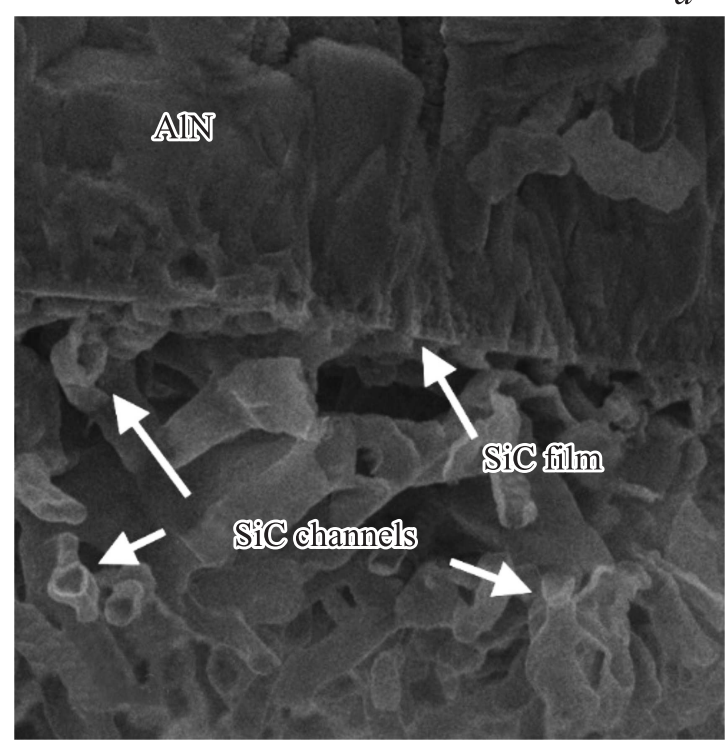

$400 \mathrm{~nm}$

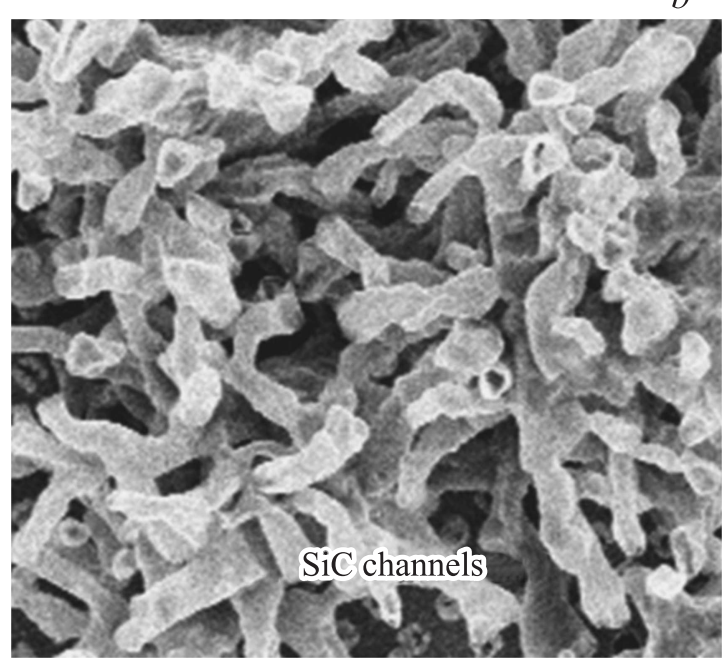

Рис. 3. СЭМ-изображения системы каналов и пор в кремнии, покрытых $\mathrm{SiC}$ и оставшихся после травления: $a-$ скол, $b-$ „обратная“ сторона $\mathrm{SiC}$.

манипуляциях распалась на кусочки с характерными размерами $1 \times 1$ мм. Структура поверхности кремния под пленкой $\mathrm{SiC}$ после травления с лежащим на нем кусочком GaN/AlN/SiC представлена на рис. $2, b$.

\section{2. Структура SiC и анализ механических напряжений}

Из рис. 1,2,3 хорошо видно, что после травления под пленкой $\mathrm{SiC}$ осталась разветвленная система пор и каналов, которая достигает толщины 2 мкм. При этом каналы полые внутри и имеют тонкие стенки (порядка десятков нанометров). Эти каналы не растворились в кислоте, следовательно, при выращивании пленки $\mathrm{SiC}$ методом [13] стенки пор, образующихся в подложке кремния, также преобразуются в карбид, что и было предположено в [13]. Отметим также, что, как ранее в работе [20] было обнаружено методом просвечивающей электронной микроскопии, под слоем пленки $\mathrm{SiC}$ находится разветвленная структура. Однако в той работе не удалось расшифровать ее. Из СЭМ-изображений также можно заключить, что поры, которые были видны на сколах пленок $\mathrm{SiC}$ в работах [12-14], являются не замкнутыми объектами, а скорее частью каналов, которые берут начало у поверхности и, имея дендритоподобную структуру, развиваются в глубь кремния. Наличие такой системы каналов может привести к тому, что механические напряжения, возникающие вследствие
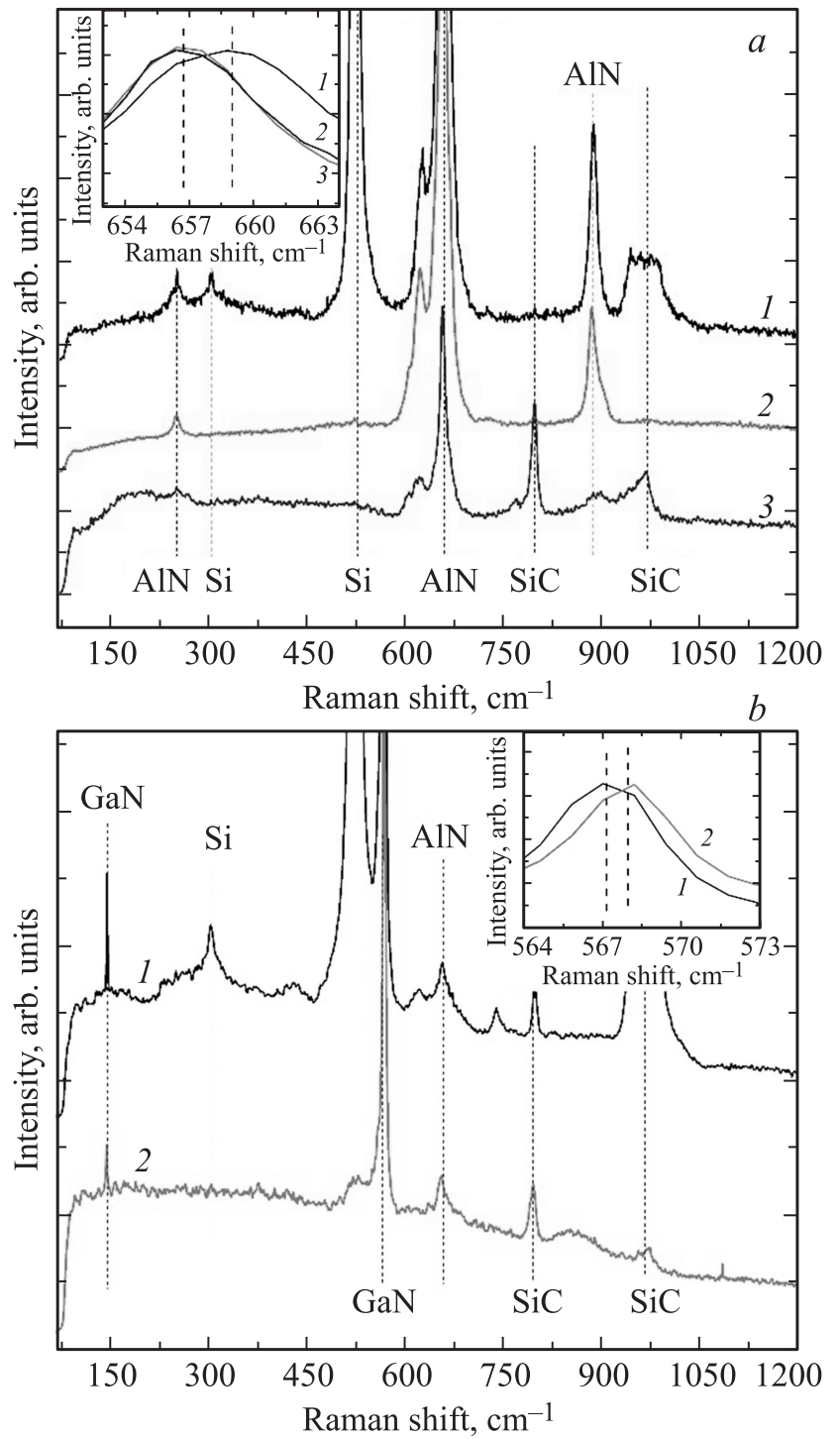

Рис. 4. Рамановские спектры полученных гетероструктур $\mathrm{AlN} / \mathrm{SiC}(a)$ и $\mathrm{GaN} / \mathrm{AlN} / \mathrm{SiC}(b)$. $a$ : спектр исходной гетероструктуры до отделения от подложки (1) и спектры $\mathrm{AlN} / \mathrm{SiC}$, снятые со стороны $\mathrm{AlN}$ (2) и со стороны $\mathrm{SiC}(3) . b$ : спектр исходной гетероструктуры до отделения от подложки (1) и спектр пленки GaN/AlN/SiC (2). На вставках крупным планом показаны положения пиков AlN $657 \mathrm{~cm}^{-1}$ и $\mathrm{GaN} 568 \mathrm{~cm}^{-1}$. 


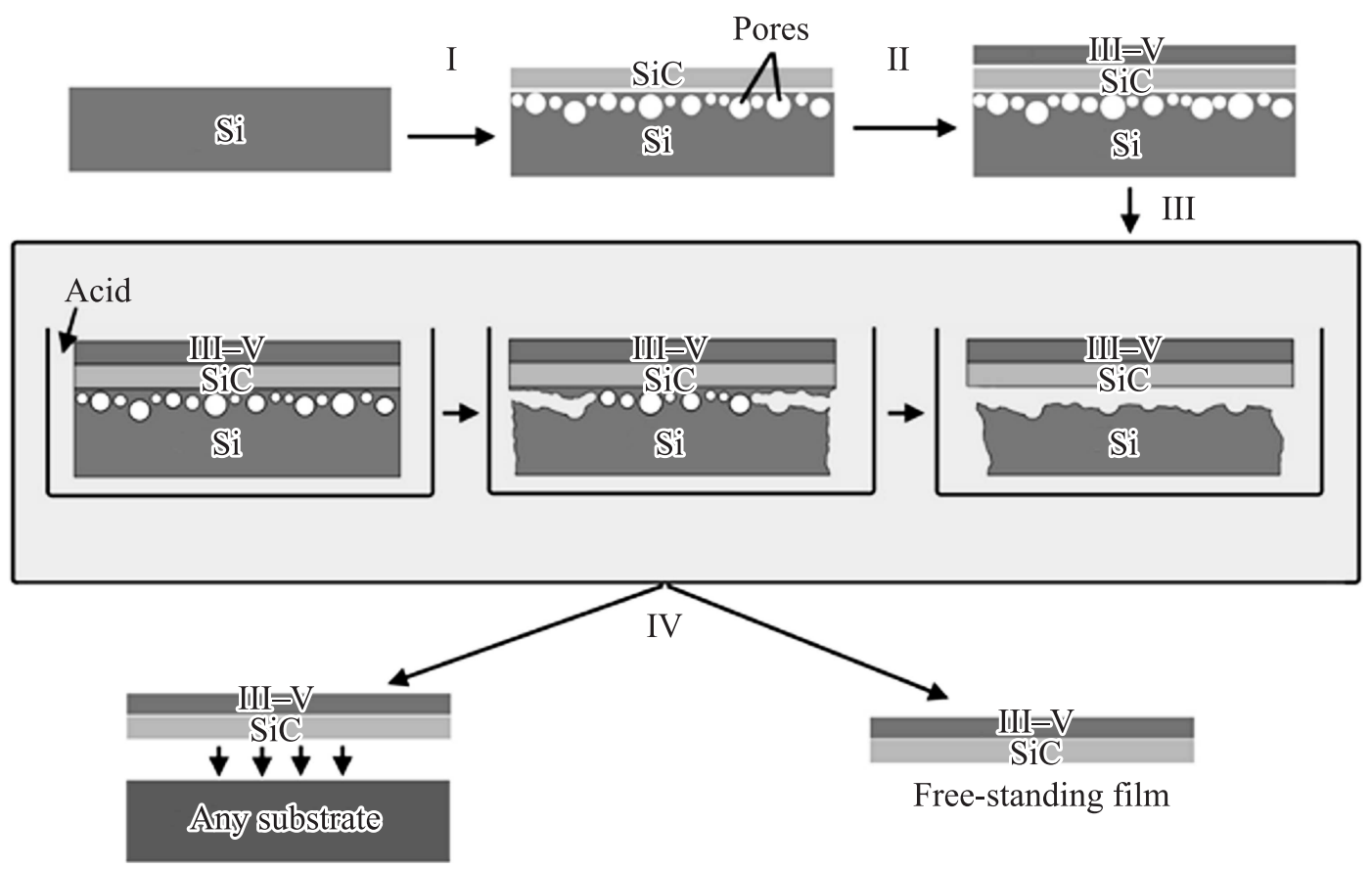

Рис. 5. Механизм перенесения пленок и гетероструктур, выращенных на $\mathrm{SiC} / \mathrm{Si}$, на любые подложки. I - нанесение на кремний слоя $\mathrm{SiC}$ методом [13]. II - осаждение требуемой гетероструктуры, III - растравливание кремния под пленкой $\mathrm{SiC}$ от краев к центру, IV - перенос пленки на другую подложку.

разности коэффициентов термического расширения и рассогласования параметров решетки, будут значительно меньше, чем в сплошных пленках, поскольку площадь соприкосновения подложки с пленкой при наличии пор становится значительно меньше. Попробуем сделать некоторые оценки. Так, коэффициент термического расширения кубического политипа $3 C$-SiC при температуре $T=900 \mathrm{~K} \alpha^{\mathrm{SiC}} \approx 3.9 \cdot 10^{-6} \mathrm{~K}^{-1}$ [21], коэффициент термического расширения гексагонального политипа $6 H$-SiC при $T=1100 \mathrm{~K} \alpha^{\mathrm{SiC}} \approx 4.46 \cdot 10^{-6} \mathrm{~K}^{-1}$ [22], а коэффициент термического расширения $\mathrm{Si}$ при $T=1000 \mathrm{~K}$ $\alpha^{\mathrm{Si}} \approx 3.6 \cdot 10^{-6} \mathrm{~K}^{-1}$ [23]. Продольные термические напряжения, возникающие в системе $\mathrm{SiC} / \mathrm{Si}$ при изменении температуры на $\Delta T$, могут быть выражены следующей формулой:

$$
\sigma_{T}=\frac{\gamma^{\mathrm{SiC}}}{1-v^{\mathrm{SiC}}}\left(\alpha^{\mathrm{Si}}-\alpha^{\mathrm{SiC}}\right) \Delta T
$$

где модуль Юнга $\mathrm{SiC} \gamma^{\mathrm{SiC}}=392-694$ ГПа, т.е. варьируется в значительных пределах, по данным различных авторов $[24,25]$. Возьмем $\gamma^{\mathrm{SiC}}=500$ ГПа, коэффициент Пуассона $v^{\mathrm{SiC}}=0.45$. Отсюда следует, что при охлаждении от температуры синтеза $T=1250^{\circ} \mathrm{C}(1523 \mathrm{~K})$ до комнатной температуры могут возникнуть напряжения сжатия для кубического политипа $3 C$ - $\mathrm{SiC}$ величиной $\sigma_{T}=-3.3 \cdot 10^{8} \mathrm{H} / \mathrm{M}^{2}$ и напряжения сжатия для гексагонального политипа $6 H-\mathrm{SiC} \sigma_{T}=-9.5 \cdot 10^{8} \mathrm{H} / \mathrm{M}^{2}$.
В некоторых работах [26,27] приводят иное значение коэффициента термического расширения кремния: $\alpha^{\mathrm{Si}} \approx 4.15 \cdot 10^{-6} \mathrm{~K}^{-1}$. В этом случае в кубическом политипе $3 C$ - $\mathrm{SiC}$ будут возникать напряжения растяжения $\sigma_{T}=2.5 \cdot 10^{8} \mathrm{H} / \mathrm{M}^{2}$, а в гексагональном $6 \mathrm{H}$-SiC - напряжения сжатия $\sigma_{T}=-3.1 \cdot 10^{8} \mathrm{H} / \mathrm{M}^{2}$. Плотность упругой энергии, запасенной в пленке, может быть записана в виде

$$
W_{T}=\frac{\sigma_{T}^{2}}{2 \gamma^{\mathrm{SiC}}}
$$

и, таким образом, для кубического политипа

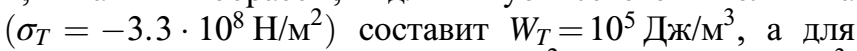

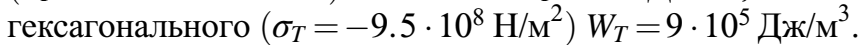
Данные значения плотности упругой энергии невелики, но из-за малой толщины пленки могут возникнуть достаточно большие градиенты механических напряжений, которые могли бы привести к образованию трещин в пленке карбида кремния. Однако обилие пор под ее поверхностью позволяет значительно снизить механические напряжения, поскольку общая площадь контакта пленка-подложка становится меньше. В общем случае эта площадь может быть уменьшена в среднем на 20-90\%, что приведет к эффективному „уменьшению“ значений коэффициентов термического расширения в такое же число раз. При этом термические напряжения станут ниже критических значений напряжений, приводящих к нарушению сплошности пленки. Важно отметить, что при росте пленок, в частности AlN, $\mathrm{GaN}, \mathrm{ZnO}$ и ряда других структур на поверхности 
$\mathrm{SiC} / \mathrm{Si}$, механические напряжения в этих слоях будут существенно меньшими, не только чем при их росте на пленках $\mathrm{SiC}$, выращенных на $\mathrm{Si}$ стандарными методами, но даже чем при росте на монокристаллах $\mathrm{SiC}$.

При дальнейшем отделении гетероструктур от подложки $\mathrm{Si}$ напряжения практически исчезают. Так, на вставках к рис. 4 изображены нормированные линии $\mathrm{AlN}$ (рис. $4, a$ ) и $\mathrm{GaN}$ (рис. $4, b$ ) до и после отделения. Видно, что после отделения их положение сместилось ближе к позициям 657 и $568 \mathrm{~cm}^{-1}$, соответствующим полностью ненапряженным кристаллам AlN и GaN по данным [28,29].

\section{5. Заключение}

В работе исследован механизм отделения пленок $\mathrm{GaN} / \mathrm{AlN} / \mathrm{SiC}$ и $\mathrm{AlN} / \mathrm{SiC}$ от подложки кремния методом химического травления. Показано, что наличие буфера $\mathrm{SiC}$, имеющего развитую подповерхностную пористую структуру, позволяет эффективно и за короткое время (порядка минут) отделять тонкую пленку или гетероструктуру от подложки кремния без использования сложных технических средств, в отличие от ионного или плазменного травления. Травление позволило впервые выявить и исследовать структуру тонкостенных пор и каналов, появляющихся в приповерхностной области кремния во время роста буферного слоя карбида кремния. Наличие такой системы позволяет „отвязать“ механические напряжения в подложке от тонкой пленки и существенно уменьшает их, таким образом нивелируя разницу в параметрах решетки или коэффициентах термического расширения. Предложенная методика отделения от подложки качественных эпитаксиальных слоев и гетероструктур широкозонных полупроводников, выращенных на нанокарбиде кремния, может найти применение при исследовании различных свойств таких отдельно стоящих структур, переносе их на другие подложки. Также они могут быть использованы для роста низкодефектных кристаллов: например, используя в качестве затравки пленку GaN/AlN/SiC/Si, возможно нарастить на нее более толстый слой $\mathrm{GaN}$ и отделить подложку кремния. Полученный ненапряженный кристалл $\mathrm{GaN} / \mathrm{AlN} / \mathrm{SiC}$, в свою очередь, может быть использован как подложка для роста других структур. Разработанный метод переноса гетероструктур на другие, не родственные с данной гетероструктурой подложки, создает беспрецедентные условия для развития микро- и наноэлектроники.

Работа выполнена при поддержке гранта РНФ № 14-12-01102. Исследования проводились с использованием оборудования уникальной научной установки „Физика, химия и механика кристаллов и тонких пленок“ ФГУП ИПМаш РАН (г. Санкт-Петербург).

Авторы выражают благодарность В.Н. Бессолову за помощь в изготовлении образцов методом HVPE и И.С. Мухину за помощь в их исследовании.

\section{Список литературы}

[1] А.А. Лебедев, В.Е. Челноков. ФТП, 33 (9), 1096 (1999).

[2] J. Kuzmík. IEEE Electron Dev. Lett., 22 (11), 510 (2001).

[3] K. Shenai, R.S. Scott, B.J. Baliga. IEEE Trans. Electron Dev., 36 (9), 1811 (1989).

[4] А.А. Лебедев, А.М. Иванов, Н.Б. Строкан. ФТП, 38 (2), 129 (2004).

[5] C.J. Eiting, V. Krishnamoorthy, S. Rodgers, T. George, J.D. Robertson, J. Brockman. Appl. Phys. Lett., 88 (6), 4101 (2006).

[6] X. Wang, G. Hu, Z. Ma, J. Ran, C. Wang, H. Xiao, J. Tang, J. Li, J. Wang, Y. Zeng, J. Li, Zh. Wang. J. Cryst. Growth, 298, 835 (2007).

[7] S.T. Sheppard, K. Doverspike, W.L. Pribble, S.T. Allen, J.W. Palmour, L.T. Kehias, T.J. Jenkins. IEEE Electron Dev. Lett., 20 (4), 161 (1999).

[8] S. Guha, N.A. Bojarczuk. Appl. Phys. Lett., 72 (4), 415 (1998).

[9] D.G. Zhao, S.J. Xu, M.H. Xie, S.Y. Tong, H. Yang. Appl. Phys. Lett., 83 (4), 677 (2003).

[10] P. Waltereit, O. Brandt, A. Trampert, M. Ramsteiner, M. Reiche, M. Qi, K.H. Ploog. Appl. Phys. Lett., 74 (24), 3660 (1999).

[11] R.S. Pengelly, S.M. Wood, J.W. Milligan, S.T. Sheppard, W.L. Pribble. IEEE Trans. Microwave Theory and Techniques, 60 (6), 1764 (2012).

[12] S.A. Kukushkin, A.V. Osipov, V.N. Bessolov, B.K. Medvedev, V.K. Nevolin, K.A. Tcarik. Rev. Adv. Mater. Sci., 17 (1/2), 1 (2008).

[13] S.A. Kukushkin, A.V. Osipov. J. Phys. D: Appl. Phys., 47 (31), 31300 (2014).

[14] S.A. Kukushkin, A.V. Osipov. J. Appl. Phys., 113 (2), 024909 (2013).

[15] С.А. Кукушкин, А.В. Осипов, М.М. Рожавская, А.В. Мясоедов, С.И. Трошков, В.В. Лундин, Л.М. Сорокин, А.Ф. Цацульников. ФТТ, 57 (9), 1850 (2015).

[16] A. Nikolaev, I. Nikitina, A. Zubrilov, M. Mynbaeva, Y. Melnik, V. Dmitriev. MRS Proc., 595, F99W6-5 (1999).

[17] Y. Kumagai, T. Nagashima, A. Koukitu. Jpn. J. Appl. Phys., 46 (5L), L389 (2007).

[18] V. Soukhoveev, O. Kovalenkov, V. Ivantsov, A. Syrkin, A. Usikov, V. Maslennikov, V. Dmitriev. Phys. Status Solidi C, 3 (6), 1653 (2006).

[19] V.N. Bessolov, D.V. Karpov, E.V. Konenkova, A.A. Lipovskii, A.V. Osipov, A.V. Redkov, I.P. Sochnikov, S.A. Kukushkin, Thin Solid Films, 606, 74 (2016).

[20] Л.М. Сорокин, Н.В. Веселов, М.П. Щеглов, А.Е. Калмыков, А.А. Ситникова, Н.А. Феоктистов, А.В. Осипов, C.А. Кукушкин. Письма ЖТФ, 34 (22), 88 (2008).

[21] D.N. Talwar, J.C. Sherbondy. Appl. Phys. Lett., 67 (22), 3301 (1995).

[22] Z. Li, R.C. Bradt. J. Amer. Ceram. Soc., 69 (12), 863 (1986).

[23] W.M. Yim, R.J. Paff. J. Appl. Phys., 45 (3), 1456 (1974).

[24] Р.С. Телятник, А.В. Осипов, С.А. Кукушкин. ФТТ, 57 (1), 153 (2015).

[25] L. Tong, M. Mehregany, L.G. Matus. Appl. Phys. Lett., 60 (24), 2992 (1992).

[26] Y. Okada, Y. Tokumaru. J. Appl. Phys., 56 (2), 314 (1984).

[27] H. Watanabe, N. Yamada, M. Okaji. Int. J. Thermophys., 25 (1), 221 (2004).

[28] J.A. Freitas, J.C. Culbertson, M.A. Mastro, Y. Kumagai, A. Koukitu. J. Cryst. Growth, 350 (1), 33 (2012). 
[29] J. Gleize, F. Demangeot, J. Frandon, M.A. Renucci, M. Kuball, B. Damilano, N. Grandjean, J. Massies. Appl. Phys. Lett., 79 (5), 686 (2001).

Редактор Л.В. Шаронова

\title{
Separation of III-N/SiC epitaxial heterostructure from Si substrate and their transfer onto other types of substrates
}

\author{
S.A. Kukushkin ${ }^{1,2,3}$, A.V. Osipov ${ }^{1,2}$, A.V. Redkov ${ }^{1,3}$ \\ ${ }^{1}$ Institute of Problems of Mechanical Engineering, \\ Russian Academy of Sciences, \\ 199178 St. Petersburg, Russia \\ 2 ITMO University, \\ 197101 St. Petersburg, Russia \\ ${ }^{3}$ Peter the Great St. Petersburg Polytechnic University, \\ 195251 St. Petersburg, Russia
}

\begin{abstract}
We developed the based on chemical etching method of separating epitaxial GaN/AlN and AlN heterostructures grown on silicon with a silicon-carbide buffer layer and transfering them onto substrates of any type. GaN/AlN/SiC and AlN/SiC heterostructures of 2.5 and $18 \mu \mathrm{m}$ thick, respectively, were separated and transferred onto the glass substrate. It is demonstrated that silicon carbide buffer layer grown by substitution of atoms on silicon has an extensive subsurface structure, which makes it easier to separate the film from the substrate and promotes relaxation of elastic energy caused by difference in the coefficients of thermal expansion of the film and the substrate. It is shown that after separation of the film from the substrate mechanical stresses in the film are almost completely relaxed.
\end{abstract}

